\title{
Assessment of the Risk of Oral Cancer Incidence in A High-Risk Population and Establishment of A Predictive Model for Oral Cancer Incidence Using A Population-Based Cohort in Taiwan
}

\author{
Li-Chen Hung ${ }^{1,2,+}{ }^{+}$, Pei-Tseng Kung ${ }^{3,4,+}$, Chi-Hsuan Lung ${ }^{5}$, Ming-Hsui Tsai ${ }^{6}$, Shih-An Liu ${ }^{7}$, \\ Li-Ting Chiu ${ }^{8}$, Kuang-Hua Huang ${ }^{8,+}+(1)$ and Wen-Chen Tsai ${ }^{8, *},+$ \\ 1 Department of Public Health, China Medical University, Taichung 40402, Taiwan; olivehung@gmail.com \\ 2 Department of Healthcare Management, Yuanpei University of Medical Technology, Hsinchu 30015, Taiwan \\ 3 Department of Healthcare Administration, Asia University, Taichung 41354, Taiwan; ptkung@asia.edu.tw \\ 4 Department of Medical Research, China Medical University Hospital, China Medical University, \\ Taichung 40402, Taiwan \\ 5 Department of Social Work, National Quemoy University, Quemoy 892, Taiwan; hsuan@nutc.edu.tw \\ 6 Department of Otolaryngology, China Medical University Hospital, Taichung 40447, Taiwan; \\ minghsui@mail.cmuh.org.tw \\ 7 Department of ENT, Taichung Veterans General Hospital, Taichung 40705, Taiwan; saliu@vghtc.gov.tw \\ 8 Department of Health Services Administration, China Medical University, Taichung 40402, Taiwan; \\ litingchiu933@gmail.com (L.-T.C.); khhuang@mail.cmu.edu.tw (K.-H.H.) \\ * Correspondence: wtsai@mail.cmu.edu.tw \\ + Authors contributed equally to this work.
}

Received: 10 December 2019; Accepted: 19 January 2020; Published: 20 January 2020

\begin{abstract}
We aimed to assess the risk of oral cancer incidence in a high-risk population, establish a predictive model for oral cancer among these high-risk individuals, and assess the predictive ability of the constructed model. Individuals aged $\geq 30$ years who had a habit of smoking or betel nut chewing and had undergone oral cancer screening in 2010 or 2011 were selected as study subjects. The incidence of oral cancer among the subjects at the end of 2014 was determined. The annual oral cancer incidence among individuals with a positive screening result was 624 per 100,000 persons, which was 6.5 times that of the annual oral cancer incidence among all individuals screened. Male sex, aged 45-64 years, divorce, low educational level, presence of diabetes, presence of other cancers, high comorbidity severity, a habit of smoking or betel nut chewing, and low monthly salary were high-risk factors for oral cancer incidence $(p<0.05)$. The area under the curve of the predictive model for oral cancer incidence was 0.73 , which indicated a good predictive ability. Therefore, the oral cancer screening policy for the high-risk population with a habit of smoking and/or betel nut chewing is beneficial for the early diagnosis of oral cancer.
\end{abstract}

Keywords: oral cancer; smoking; betel nut chewing; screening; prediction

\section{Introduction}

There are about 657,000 new cases of oral and throat cancer worldwide each year, resulting in more than 330,000 deaths; based on the exposure to risk factors, oral cancer in Central and South Asia is relatively severe [1]. According to the International Agency for Research on Cancer, some Asia-Pacific countries had the top three rates of oral cancer in 2018 [2-5]. The crude incidence rate of oral cancer in Taiwan is 32.46 per 100,000 persons, which is the highest worldwide [6]. Oral cancer is also the most common type of head and neck cancer in Taiwan, with the incidence rate among men being 10.9 times 
higher than that among women [6]. By comparing the incidence rates of various cancers in Taiwan, it can be observed that oral cancer ranks fifth among the top 10 causes of deaths due to cancer and has been the fourth most common cancer among men for 12 consecutive years since 2003 [6]. Therefore, the prevention and control of oral cancer are regarded as key health issues in Taiwan.

The betel nut chewing culture unique to Asians is also a key risk factor that has been highlighted by many researchers [7-14]. In a report by the International Agency for Research on Cancer (IARC), betel nut has been cited as a group 1 carcinogen [15]. As approximately $86 \%$ of Taiwanese oral cancer patients are habitual betel nut chewers and betel nuts are readily available in Taiwan [6], a greater amount of attention should be focused on the health hazards associated with betel nut chewing.

According to statistics from the 2015 Cancer Registry Annual Report issued by the Health Promotion Administration of the Ministry of Health and Welfare of Taiwan, the risk of cancer incidence is higher among Taiwanese men than among Taiwanese women, and the age-specific cancer incidence increases gradually with age [6]. Similarly, the global age-standardized incidence rate (ASIR) for all cancers per 100,000 persons among men is significantly higher than that among women, and the cancer incidence rates for both men and women increase with age [16].

Health-related behaviors are closely linked to oral cancer, with excessive drinking, smoking, and betel nut chewing leading to an increased risk of oral cancer incidence [17-23], and HPV infection, poor oral health, Lichen Planus, etc. have also been pointed out in many literatures as risk factors for oral cancer [22,24-29]. In India, chewing tobacco is the strongest predictor of upper gastrointestinal cancer, and its effect is even greater than those of drinking or smoking. The combined effects of smoking and drinking increases this population's risk of cancer by a factor of 12 when compared to those who have never smoked or drank [30]. Data from pioneering research by Taiwanese researchers indicate that the risk of oral cancer incidence among individuals with concurrent habits of smoking, drinking, and betel nut chewing is 123 times higher than that among the general population. However, there was only a statistically significant association between oral cancer and chewing betel nuts $[13,31]$. In many studies, researchers have asserted that socioeconomic status (SES), which includes educational level, income, and occupation, is also linked to the risk of oral cancer incidence [32-36]. Generally, the risk of oral cancer incidence is lower in individuals with higher educational and income levels. However, with the progression of time, the difference in the risk of oral cancer incidence between high-income earners and low-income earners has gradually reduced [36]. Regarding the degree of urbanization, statistics reported by the American Cancer Society have indicated that the ASIR for all cancers per 100,000 persons in highly developed regions is higher than the corresponding cancer incidence rate in less developed regions for both men and women [37], which shows that regions with a higher level of urbanization have a greater risk of cancer incidence. In North America and Europe, "high-risk" human papillomavirus infection is responsible for the increasing percentage of young people with oropharyngeal cancer [22,26]. Relevant research has indicated that HPV has a statistically significant correlation with oral cancer $[22,24,26,28,29]$. The prevalence of HPV in oropharyngeal head and neck cancer (OPC) has increased over time, with an increase within 10 years from $40.5 \%$ before 2000 to $72.2 \%$ in 2005-2009 [26,27], showing that HPV infection is an important indicator of oral cancer risk. In addition, relationships between poor oral hygiene, periodontal disease, chronic candidiasis, herpesvirus infection, and oral cancer have been proposed in many studies [25,27].

In the present study, by analyzing national data on oral cancer screening in Taiwan with consideration of the time factor, we attempted to assess the risk of oral cancer incidence in a high-risk population, establish a predictive model for the risk of oral cancer incidence among these individuals, and assess the predictive ability of the established model. 


\section{Materials and Methods}

\subsection{Study Subjects}

Individuals aged 30 years and above who had a habit of smoking or betel nut chewing and had underwent oral cancer screening in 2010 or 2011 were followed up to the end of 2014 to determine the oral cancer morbidity status. All subjects included in the oral cancer screening files for 2010 and 2011 were included in the analysis. Only those who had oral cancer before the screening were excluded.

\subsection{Data Sources}

The data used in the present study were obtained from databases and records provided by the Department of Statistics of the Ministry of Health and Welfare of Taiwan, which included oral cancer screening records [38], cancer registry records [39], the National Health Insurance Database, and household registration records from the Ministry of the Interior of Taiwan. The criteria for extracting variables from the database are based on the demographic variables and health-related factors related to the incidence of oral cancer shown in previous literatures [11,27,33,40-57]. First, the basic data, oral screening data, and data on health-related behaviors of the subjects were extracted from the cancer screening records. This was followed by the extraction of data such as date and method of confirmed diagnosis of oral cancer from the cancer registry records and the extraction of data on other catastrophic illnesses from the Registry for Catastrophic Illness Patients database. Data on variables such as sex, age, SES, health status and utilization of preventive health services were extracted from the National Health Insurance Database. Other data such as those regarding the degree of urbanization, educational level, marital status, and race were extracted from the household registration records [58].

\subsection{Definition of Variables}

The variables used in the present study included the following: sex, age, educational level, marital status, indigenous race, degree of urbanization of the place of residence, presence or absence of diabetes, presence or absence of other cancers $[11,27,33,40-57]$, Charlson comorbidity index (CCI), presence or absence of other catastrophic illnesses, health-related behaviors, and monthly salary. The degrees of urbanization of the places of residence of the participants were classified into seven levels, with level 1 corresponding to regions with the highest degree of urbanization and level 7 corresponding to regions with the lowest degree of urbanization. The CCI proposed by Deyo et al. was used as a measure of comorbidity severity [59]. The presence or absence of catastrophic illnesses was determined based on the definition of catastrophic illnesses stated by the National Health Insurance Administration of Taiwan in the Registry for Catastrophic Illness Patients, which includes 30 categories of diseases such as cancer, stroke, and renal disease requiring dialysis [60]. Individuals with other catastrophic diseases other than malignant neoplasms were classified as having other catastrophic illnesses [60]. The health-related behavior categories included smoking, betel nut chewing, and concurrent smoking and betel nut chewing habits.

\subsection{Statistical Analysis}

A univariate Poisson regression analysis was first performed and the incidence density ratio (IDR) was used to indicate the annual risk of oral cancer incidence per 100,000 persons. Subsequently, the log-rank test was used to analyze the correlations between the various factors and risk of oral cancer incidence, and a Cox proportional hazards $(\mathrm{PH})$ model was used to examine the risk factors and curve for the risk of oral cancer incidence. The onset of oral cancer before the end of 2014 was defined as an event and the observation period was calculated up to the time of onset. The non-occurrence of oral cancer before the end of 2014 was defined as a censor and the observation period was assessed up to the end of 2014.

We used a logistic regression model as a predictive model, and the area under the receiver operating characteristic (ROC) curve (AUC) was determined to assess the ability of the model to 
predict the risk of oral cancer incidence. The ROC curve was generated by plotting sensitivity (i.e., true positive rate) against 1 -specificity (i.e., false positive rate). The AUC is a measure of the classification ability of the model. AUC values are generally interpreted as follows, with higher values indicating better classification ability: <0.5: test not useful, $0.5-0.6$ : bad, $0.6-0.7$ : sufficient, $0.7-0.8$ : good, $0.8-0.9$ : very good, 0.9-1.0: excellent [61].

\section{Results}

In the present study, the annual cancer morbidity per 100,000 persons among the Taiwanese population with smoking and betel nut chewing habits who had undergone oral cancer screening was measured using the IDR. The annual oral cancer incidence rate among the screened individuals was 96 per 100,000 persons (Table 1). The incidence rate among men was 5.5 times higher than that among women, and the incidence rate among individuals aged 45-64 years was significantly higher than that among individuals aged $<45$ years. Notably, close to $5 \%$ of oral cancer patients were aged below 45 years; this is indicative of a rising cancer incidence among the younger population, which warrants attention. When the relationships between incidence rate and the various SES-related factors were examined, we found that the incidence rate decreased with increasing educational level, divorcees had a significantly higher incidence rate than married individuals, individuals residing in regions with a lower degree of urbanization had a higher incidence rate, and the incidence rate decreased with increasing income level. Among individuals with different health-related behaviors, the risk of oral cancer incidence among betel nut chewers was significantly higher than that among smokers. Individuals who had concurrent habits of smoking and betel nut chewing had a higher oral cancer risk than individuals who only had either a smoking habit or a betel nut chewing habit. The incidence of oral cancer among individuals who were diabetic prior to screening was 1.62 times higher than that among those who were not diabetic. Individuals with other cancers prior to screening had an oral cancer incidence rate that was 2.13 times higher than that among individuals without other cancers. The cancer incidence rate increased with comorbidity severity and was higher among individuals with other catastrophic illnesses than among those without other catastrophic illnesses.

Table 1. Basic information and rate of oral cancer incidence in the high-risk population screened for oral cancer.

\begin{tabular}{|c|c|c|c|c|c|c|c|c|c|c|}
\hline \multirow{2}{*}{ Variable } & \multicolumn{5}{|c|}{ All Screened Persons } & \multicolumn{5}{|c|}{ Positive Cases } \\
\hline & $N$ & $n$ & Mean & IDR $^{a}$ & $p$-Value ${ }^{b}$ & $N$ & $n$ & Mean & IDR $^{a}$ & $p$-Value ${ }^{b}$ \\
\hline Total & $1,719,191$ & 6275 & 3.80 & 96 & - & 117,697 & 2777 & 3.78 & 624 & - \\
\hline \multicolumn{11}{|c|}{ Sex } \\
\hline Female & 347,477 & 267 & 3.77 & 20 & - & 8163 & 91 & 3.78 & 295 & - \\
\hline Male & $1,371,714$ & 6008 & 3.81 & 115 & $<0.001$ & 109,534 & 2686 & 3.78 & 649 & $<0.001$ \\
\hline \multicolumn{11}{|c|}{ Age, years } \\
\hline$<45$ & 613,275 & 1306 & 3.85 & 55 & - & 42,531 & 652 & 3.84 & 400 & - \\
\hline $45-54$ & 445,594 & 2085 & 3.84 & 122 & $<0.001$ & 35,937 & 956 & 3.80 & 700 & $<0.001$ \\
\hline $55-64$ & 328,320 & 1757 & 3.81 & 140 & $<0.001$ & 24,712 & 793 & 3.75 & 855 & $<0.001$ \\
\hline$\geq 65$ & 332,002 & 1127 & 3.66 & 93 & $<0.001$ & 14,517 & 376 & 3.62 & 716 & $<0.001$ \\
\hline \multicolumn{11}{|c|}{ Educational level } \\
\hline Elementary and below & 399,726 & 1915 & 3.72 & 129 & - & 24,082 & 768 & 3.68 & 866 & - \\
\hline Junior high school & 448,680 & 1987 & 3.82 & 116 & $<0.001$ & 35,535 & 930 & 3.78 & 692 & $<0.001$ \\
\hline Senior high school & 561,113 & 1971 & 3.83 & 92 & $<0.001$ & 43,869 & 912 & 3.81 & 545 & $<0.001$ \\
\hline Tertiary & 293,723 & 401 & 3.83 & 36 & $<0.001$ & 13,600 & 166 & 3.85 & 317 & $<0.001$ \\
\hline Unknown & 15,949 & 1 & 3.93 & 2 & $<0.001$ & 611 & 1 & 3.93 & 42 & 0.002 \\
\hline \multicolumn{11}{|c|}{ Marital status } \\
\hline Married & $1,224,584$ & 4614 & 3.82 & 99 & - & 83,139 & 2030 & 3.80 & 642 & - \\
\hline Divorced & 176,592 & 869 & 3.78 & 130 & $<0.001$ & 15,254 & 393 & 3.74 & 688 & 0.222 \\
\hline Widowed & 89,821 & 251 & 3.59 & 78 & $<0.001$ & 3799 & 90 & 3.56 & 666 & 0.736 \\
\hline Unmarried & 211,957 & 540 & 3.79 & 67 & $<0.001$ & 14,869 & 263 & 3.76 & 471 & $<0.001$ \\
\hline Unknown & 16,237 & 1 & 3.93 & 2 & $<0.001$ & 636 & 1 & 3.92 & 40 & 0.006 \\
\hline
\end{tabular}


Table 1. Cont.

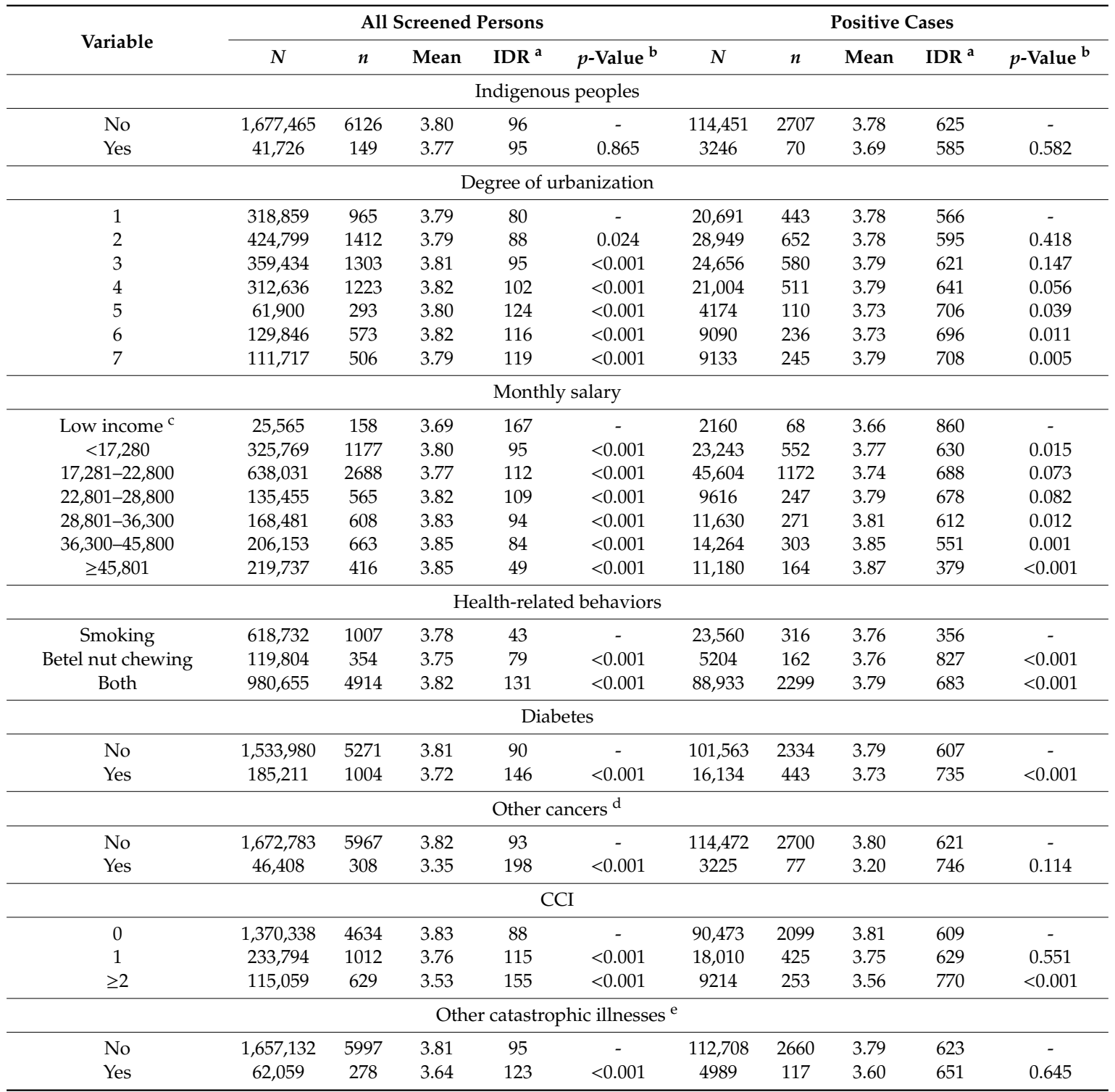

a per 100,000 person years; ${ }^{b}$ univariate Poisson regression; ${ }^{c}$ In this study, "low income" was based on the definition of low income households in Taiwan; ${ }^{\mathrm{d}}$ In this study, "other cancer" is defined as other cancers after excluding oral cancer in the Registry for Catastrophic Illness Patients Database; " In this study, "other catastrophic illnesses" are defined as, in addition to malignant cancer and type 1 diabetes (listed as independent variables), the other 28 categories of diseases registered in the Registry for Catastrophic Illness Patients Database (e.g., dialysis, rare diseases, stroke, hemophilia, etc.).

When the data of individuals with positive screening results were compared with those of all screened individuals, we found that the annual oral cancer incidence rate among individuals with positive screening results was 624 per 100,000 persons, which was 6.5 times higher than that among all screened individuals (96 per 100,000 persons). This indicates that screening is indeed beneficial toward identifying the population with a high-risk for oral cancer incidence. If timely medical consultations and continuous follow-up can be provided to the population with positive screening results, the risk of oral cancer incidence in these individuals should be effectively reduced.

By considering the time of cancer incidence, the relationships between the various variables and the risk of cancer incidence were determined using the log-rank test. Sex, age, educational level, marital status, degree of urbanization of the place of residence, presence or absence of diabetes, presence or absence of other cancers, comorbidity severity, presence or absence of other catastrophic illnesses, 
smoking and betel nut chewing habits, and monthly salary were correlated with the risk of oral cancer incidence in screened individuals $(p<0.05)$ (Table 2).

Table 2. Bivariate analysis of the high-risk populations with and without oral cancer who had undergone oral cancer screening (observed until 2014).

\begin{tabular}{|c|c|c|c|c|c|c|c|}
\hline \multirow{2}{*}{ Variable } & \multirow[b]{2}{*}{$n$} & \multirow[b]{2}{*}{$\%$} & \multicolumn{2}{|c|}{ No cancer } & \multicolumn{2}{|c|}{ Cancer } & \multirow[b]{2}{*}{$p$-Value ${ }^{\mathrm{a}}$} \\
\hline & & & $n$ & $\%$ & $n$ & $\%$ & \\
\hline Total & $1,719,191$ & 100.00 & $1,712,916$ & 99.64 & 6275 & 0.36 & - \\
\hline Sex & & & & & & & $<0.001$ \\
\hline Female & 347,477 & 20.21 & 347,210 & 99.92 & 267 & 0.08 & \\
\hline Male & $1,371,714$ & 79.79 & $1,365,706$ & 99.56 & 6008 & 0.44 & \\
\hline Age, years & & & & & & & $<0.001$ \\
\hline$<45$ & 613,275 & 35.67 & 611,969 & 99.79 & 1306 & 0.21 & \\
\hline $45-54$ & 445,594 & 25.92 & 443,509 & 99.53 & 2085 & 0.47 & \\
\hline $55-64$ & 328,320 & 19.10 & 326,563 & 99.46 & 1757 & 0.54 & \\
\hline$\geq 65$ & 332,002 & 19.31 & 330,875 & 99.66 & 1127 & 0.34 & \\
\hline Educational level & & & & & & & $<0.001$ \\
\hline Elementary and below & 399,726 & 23.25 & 397,811 & 99.52 & 1915 & 0.48 & \\
\hline Junior high school & 448,680 & 26.10 & 446,693 & 99.56 & 1987 & 0.44 & \\
\hline Senior high school & 561,113 & 32.64 & 559,142 & 99.65 & 1971 & 0.35 & \\
\hline Tertiary & 293,723 & 17.08 & 293,322 & 99.86 & 401 & 0.14 & \\
\hline Unknown & 15,949 & 0.93 & 15,948 & 99.99 & 1 & 0.01 & \\
\hline Marital status & & & & & & & $<0.001$ \\
\hline Married & $1,224,584$ & 71.23 & $1,219,970$ & 99.62 & 4614 & 0.38 & \\
\hline Divorce & 176,592 & 10.27 & 175,723 & 99.51 & 869 & 0.49 & \\
\hline Widowed & 89,821 & 5.22 & 89,570 & 99.72 & 251 & 0.28 & \\
\hline Unmarried & 211,957 & 12.33 & 211,417 & 99.75 & 540 & 0.25 & \\
\hline Unknown & 16,237 & 0.94 & 16,236 & 99.99 & 1 & 0.01 & \\
\hline Indigenous peoples & & & & & & & 0.763 \\
\hline No & $1,677,465$ & 97.57 & $1,671,339$ & 99.63 & 6126 & 0.37 & \\
\hline Yes & 41,726 & 2.43 & 41,577 & 99.64 & 149 & 0.36 & \\
\hline Degree of urbanization & & & & & & & $<0.001$ \\
\hline 1 & 318,859 & 18.55 & 317,894 & 99.70 & 965 & 0.30 & \\
\hline 2 & 424,799 & 24.71 & 423,387 & 99.67 & 1412 & 0.33 & \\
\hline 3 & 359,434 & 20.91 & 358,131 & 99.64 & 1303 & 0.36 & \\
\hline 4 & 312,636 & 18.19 & 311,413 & 99.61 & 1223 & 0.39 & \\
\hline 5 & 61,900 & 3.60 & 61,607 & 99.53 & 293 & 0.47 & \\
\hline 6 & 129,846 & 7.55 & 129,273 & 99.56 & 573 & 0.44 & \\
\hline 7 & 111,717 & 6.50 & 111,211 & 99.55 & 506 & 0.45 & \\
\hline Diabetes & & & & & & & $<0.001$ \\
\hline No & $1,533,980$ & 89.23 & $1,528,709$ & 99.66 & 5271 & 0.34 & \\
\hline Yes & 185,211 & 10.77 & 184,207 & 99.46 & 1004 & 0.54 & \\
\hline Other cancers & & & & & & & $<0.001$ \\
\hline No & $1,672,783$ & 97.30 & $1,666,816$ & 99.64 & 5967 & 0.36 & \\
\hline Yes & 46,408 & 2.70 & 46,100 & 99.34 & 308 & 0.66 & \\
\hline CCI & & & & & & & $<0.001$ \\
\hline 0 & $1,370,338$ & 79.71 & $1,365,704$ & 99.66 & 4634 & 0.34 & \\
\hline 1 & 233,794 & 13.60 & 232,782 & 99.57 & 1012 & 0.43 & \\
\hline$\geq 2$ & 115,059 & 6.69 & 114,430 & 99.45 & 629 & 0.55 & \\
\hline Other catastrophic illnesses & & & & & & & $<0.001$ \\
\hline No & $1,657,132$ & 96.39 & $1,651,135$ & 99.64 & 5997 & 0.36 & \\
\hline Yes & 62,059 & 3.61 & 61,781 & 99.55 & 278 & 0.45 & \\
\hline
\end{tabular}


Table 2. Cont.

\begin{tabular}{|c|c|c|c|c|c|c|c|}
\hline \multirow{2}{*}{ Variable } & \multirow[b]{2}{*}{$n$} & \multirow[b]{2}{*}{$\%$} & \multicolumn{2}{|c|}{ No cancer } & \multicolumn{2}{|c|}{ Cancer } & \multirow[b]{2}{*}{$p$-Value ${ }^{\mathrm{a}}$} \\
\hline & & & $n$ & $\%$ & $n$ & $\%$ & \\
\hline Health-related behaviors & & & & & & & $<0.001$ \\
\hline Smoking & 618,732 & 35.99 & 617,725 & 99.84 & 1007 & 0.16 & \\
\hline Betel nut chewing & 119,804 & 6.97 & 119,450 & 99.70 & 354 & 0.30 & \\
\hline Both & 980,655 & 57.04 & 975,741 & 99.50 & 4914 & 0.50 & \\
\hline Monthly salary & & & & & & & $<0.001$ \\
\hline Low income & 25,565 & 1.49 & 25,407 & 99.38 & 158 & 0.62 & \\
\hline$<17,280$ & 325,769 & 18.95 & 324,592 & 99.64 & 1177 & 0.36 & \\
\hline $17,281-22,800$ & 638,031 & 37.11 & 635,343 & 99.58 & 2688 & 0.42 & \\
\hline $22,801-28,800$ & 135,455 & 7.88 & 134,890 & 99.58 & 565 & 0.42 & \\
\hline $28,801-36,300$ & 168,481 & 9.80 & 167,873 & 99.64 & 608 & 0.36 & \\
\hline $36,300-45,800$ & 206,153 & 11.99 & 205,490 & 99.68 & 663 & 0.32 & \\
\hline$\geq 45,801$ & 219,737 & 12.78 & 219,321 & 99.81 & 416 & 0.19 & \\
\hline
\end{tabular}

Using a Cox PH model, we investigated the risks of oral cancer incidence in individuals screened for oral cancer and the relevant factors. Sex, age, educational level, marital status, presence or absence of diabetes, presence or absence of other cancers, comorbidity severity, smoking and betel nut chewing habits, and monthly salary influenced oral cancer incidence among individuals who had undergone oral cancer screening (Table 3). Among the individuals screened, men had a higher risk of oral cancer incidence (hazard ratio $(\mathrm{HR})=5.72$ ). In particular, the risk of oral cancer incidence in individuals with an educational level of junior high school and above was $0.37-0.89$ times higher than that among individuals with an educational level of elementary school and below. Individuals with a habit of betel nut chewing ( $\mathrm{HR}=2.12)$ or concurrent habits of smoking and betel nut chewing $(\mathrm{HR}=2.29)$ also had a higher risk of oral cancer incidence than individuals who only had the habit of smoking.

Table 3. Risk of oral cancer incidence and related factors in the high-risk population who had undergone oral cancer screening.

\begin{tabular}{ccccc}
\hline Sex & Adjusted HR & \multicolumn{2}{c}{$\mathbf{9 5 \%}$ CI } & $p$-Value ${ }^{\mathbf{a}}$ \\
\hline Female (ref) & - & - & - & - \\
Male & 5.72 & 5.04 & 6.49 & $<0.001$ \\
\hline Age, years & & & & \\
$<45$ (ref) & - & - & - & - \\
$45-54$ & 1.88 & 1.75 & 2.02 & $<0.001$ \\
55-64 & 1.93 & 1.77 & 2.09 & $<0.001$ \\
$\geq 65$ & 1.05 & 0.95 & 1.16 & 0.375 \\
\hline Educational level & & & & \\
Elementary and below (ref) & - & - & - & - \\
Junior high school & 0.89 & 0.83 & 0.96 & 0.003 \\
Senior high school & 0.76 & 0.71 & 0.82 & $<0.001$ \\
Tertiary & 0.37 & 0.33 & 0.42 & $<0.001$ \\
Unknown & 0.73 & 0.00 & 2597.95 & 0.939 \\
Marital status & & & & \\
Married (ref) & - & - & - & - \\
Divorced & 1.35 & 1.25 & 1.45 & $<0.001$ \\
Widowed & 1.07 & 0.93 & 1.22 & 0.341 \\
Unmarried & 0.86 & 0.79 & 0.95 & 0.003 \\
Unknown & 0.03 & 0.00 & 90.44 & 0.379 \\
\hline
\end{tabular}


Table 3. Cont.

\begin{tabular}{|c|c|c|c|c|}
\hline Sex & Adjusted HR & \multicolumn{2}{|c|}{$95 \% \mathrm{CI}$} & $p$-Value ${ }^{\text {a }}$ \\
\hline \multicolumn{5}{|l|}{ Indigenous peoples } \\
\hline No (ref) & - & - & - & - \\
\hline Yes & 1.02 & 0.86 & 1.21 & 0.821 \\
\hline \multicolumn{5}{|c|}{ Degree of urbanization } \\
\hline 1 (ref) & - & - & - & - \\
\hline 2 & 1.04 & 0.96 & 1.13 & 0.335 \\
\hline 3 & 0.97 & 0.89 & 1.05 & 0.454 \\
\hline 4 & 0.92 & 0.85 & 1.01 & 0.068 \\
\hline 5 & 0.96 & 0.84 & 1.10 & 0.552 \\
\hline 6 & 0.97 & 0.87 & 1.08 & 0.620 \\
\hline 7 & 1.00 & 0.89 & 1.11 & 0.956 \\
\hline \multicolumn{5}{|l|}{ Monthly salary } \\
\hline Low income (ref) & - & - & - & - \\
\hline$<17,280$ & 0.75 & 0.63 & 0.89 & 0.001 \\
\hline $17,281-22,800$ & 0.74 & 0.63 & 0.87 & $<0.001$ \\
\hline $22,801-28,800$ & 0.74 & 0.62 & 0.89 & 0.001 \\
\hline $28,801-36,300$ & 0.65 & 0.55 & 0.78 & $<0.001$ \\
\hline $36,300-45,800$ & 0.55 & 0.46 & 0.66 & $<0.001$ \\
\hline$\geq 45,801$ & 0.44 & 0.37 & 0.54 & $<0.001$ \\
\hline \multicolumn{5}{|c|}{ Health-related behaviors } \\
\hline Smoking (ref) & - & - & - & - \\
\hline Betel nut chewing & 2.12 & 1.87 & 2.39 & $<0.001$ \\
\hline Both & 2.29 & 2.14 & 2.46 & $<0.001$ \\
\hline \multicolumn{5}{|l|}{ Diabetes } \\
\hline No (ref) & - & - & - & - \\
\hline Yes & 1.20 & 1.12 & 1.29 & $<0.001$ \\
\hline \multicolumn{5}{|l|}{ Other cancer } \\
\hline No (ref) & - & - & - & - \\
\hline Yes & 1.91 & 1.70 & 2.14 & $<0.001$ \\
\hline \multicolumn{5}{|l|}{ CCI } \\
\hline 0 (ref) & - & - & - & - \\
\hline 1 & 1.08 & 1.01 & 1.16 & 0.025 \\
\hline$\geq 2$ & 1.27 & 1.16 & 1.39 & $<0.001$ \\
\hline \multicolumn{5}{|c|}{ Other catastrophic illnesses } \\
\hline No (ref) & - & - & - & - \\
\hline Yes & 1.06 & 0.94 & 1.20 & 0.352 \\
\hline
\end{tabular}

Figure 1 shows the risk of oral cancer incidence in the high-risk population who had undergone oral cancer screening. It can be observed that when other variables were controlled, the risk of oral cancer incidence increased as the time elapsed after oral cancer screening increased, with the extent of increase also increasing with time. The accuracy of the model in predicting the risk of oral cancer incidence in the high-risk population was assessed using the AUC (Figure 2). The calculated AUC value for the predictive model was 0.73 , which indicates that the model has a good predictive ability [61]. The sensitivity and specificity was $77.1 \%$ and $56.4 \%$, respectively. Positive predictive value was $63.9 \%$ and negative predictive value was $71.1 \%$, indicating that this model has a good level of validity. 


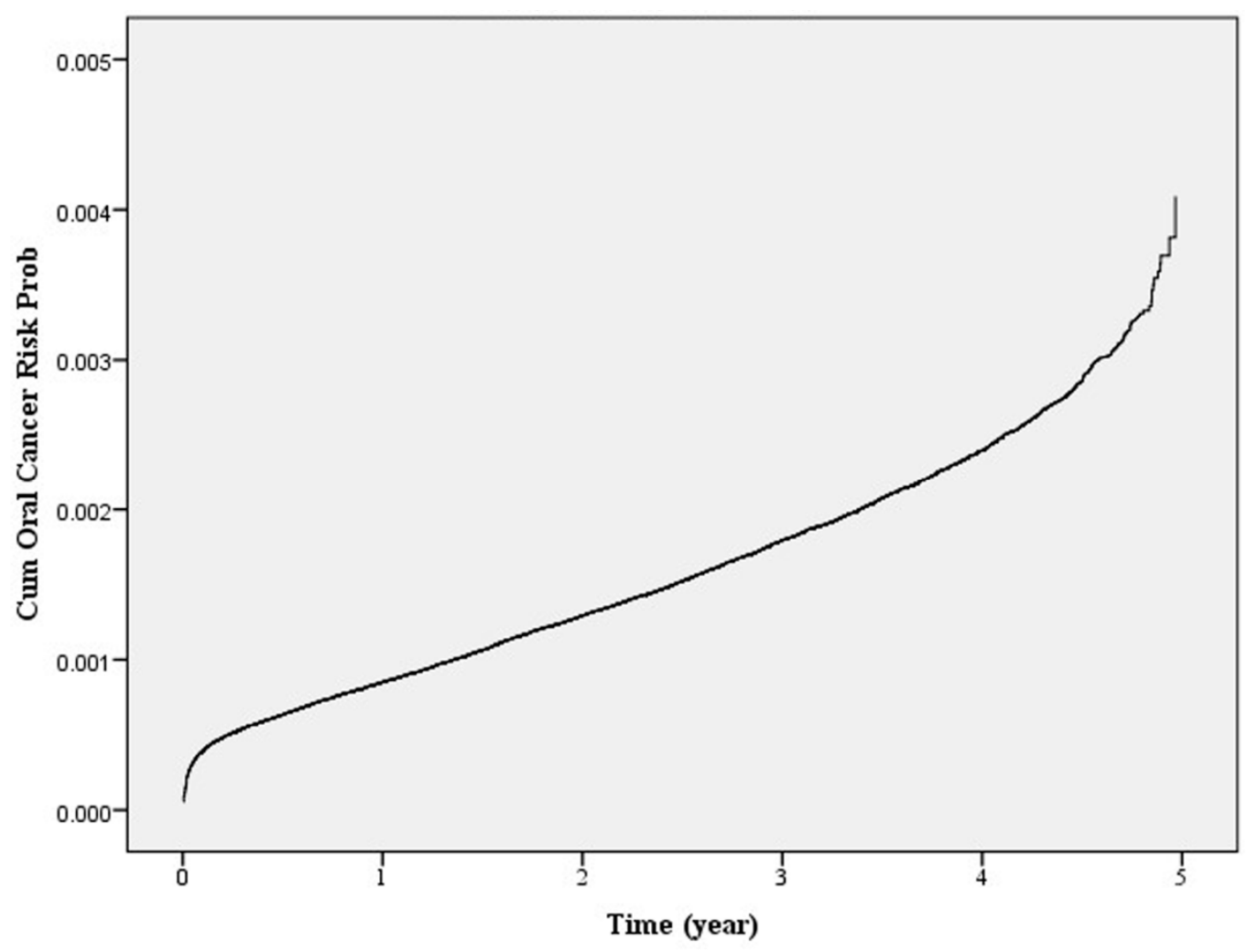

Figure 1. Risk of oral cancer in the high-risk population who had undergone oral cancer screening.

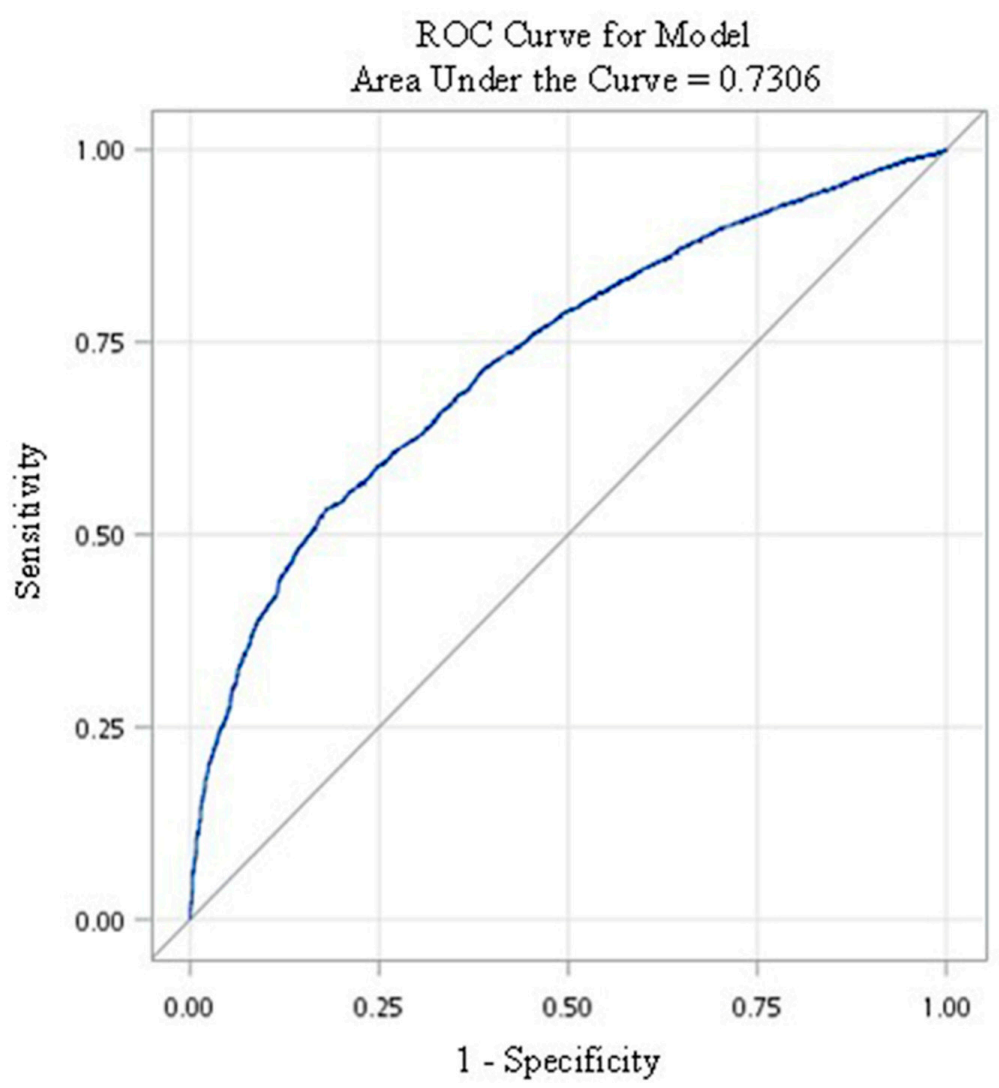

Figure 2. Receiver operating characteristic (ROC) curve of the predictive model for the high-risk population who had undergone oral cancer screening. 


\section{Discussion}

The annual oral cancer incidence rate among the screened individuals was 96 per 100,000 persons-such a high incidence is significantly higher than in other countries [2-5]. Our results indicate that the annual oral cancer incidence rate per 100,000 persons among individuals with positive screening results was 6.5 times higher than among all individuals screened. This shows that the implementation of the oral cancer screening program is beneficial toward the early diagnosis of oral cancer at the early stage. According to the National Cancer Prevention and Control Program of Taiwan, the follow-up rate for cases of positive oral cancer screening results should reach $80 \%$ by 2018 [62]. As of the end of 2018, the rate of confirmed diagnosis of oral cancer among high-risk individuals aged $\geq 30$ years with positive screening results was as high as $79.2 \%$. However, close to $21 \%$ of cases with abnormalities did not make return hospital visits for follow-up [63], and an investigation revealed that this was attributed to the lack of close monitoring and subsequent follow-up of the cases by medical institutions.

When the relationships between incidence rate and the various SES-related factors were examined, we found that the incidence rate decreased with increasing educational level; this result is consistent with previous research findings [22,34-36,64]. Therefore, incidence rates decrease as income levels increase, which is similar to the results of previous studies [33,35,40,41,45,47,49,50,56,65,66]. Individuals aged 45-64 years had a higher risk of oral cancer incidence than the younger population ( $\mathrm{HR}=1.88-1.99)$, but the risk of cancer incidence was not significantly higher in individuals aged $\geq 65$ years than in the younger population. This may be related to the greater number of competing causes of death in the population aged $\geq 65$ years. When the influence of health-related behaviors was investigated, it was found that people who chew betel nuts are 2.12 times more likely to develop oral cancer if they use smoking as a baseline for comparison $(\mathrm{HR}=2.12)$; the results showed that chewing betel nut had a significantly higher oral cancer incidence risk than those who only had a habit of smoking. Individuals who had concurrent habits of smoking and betel nut chewing had a significantly higher oral cancer incidence rate than those who only had a habit of smoking $(H R=2.29)$. This indicates that betel nut chewing exerts a significantly greater influence on the rate of oral cancer incidence than smoking $[18,31,53,55]$. Individuals with diabetes $(H R=1.20)$, other cancers $(H R=1.91)$, and CCI $>2(\mathrm{HR}=1.27)$ also had a higher relative risk of oral cancer. Based on the above results, confirmed diagnoses should be performed in a timely manner for individuals who have diabetes or other cancers to achieve diagnosis and appropriate treatment at the early stage and to increase the survival rate of these individuals.

To assess the accuracy of our predictive model for the risk of oral cancer incidence in the high-risk population, a ROC curve was plotted and the AUC calculated. An AUC of 0.73 was obtained, which indicates that the model has good predictive ability for the risk of oral cancer incidence [61]. Studies from India related to the upper gastrointestinal tract showed that the prediction of cancer risk based on the total risk score of chewing tobacco, smoking, drinking, and other unhealthy lifestyle habits in the general population has a high level of predictive power and validity [30,67]. This shows that unhealthy lifestyle habits are indeed an important indicator for predicting the risk of upper gastrointestinal cancer.

To prevent the hazardous effects of oral cancer on the health of the public, the Health Promotion Administration of Taiwan launched an oral cancer screening program in 1999. The program was further expanded in June 2013 to include individuals aged $\geq 30$ years with the habits of betel nut chewing and smoking as well as indigenous people aged 18 years and above with a habit of betel nut chewing with the aim of achieving early detection and administration of appropriate treatment [68]. The World Health Organization (WHO) estimated that the probability of preventing cancer-related death may exceed $30 \%$ with the maintenance of regular good lifestyle habits and reduced contact with carcinogens [69]. As oral mucosal examinations can effectively reduce the oral cancer mortality rate by $40 \%$ and the five-year survival rate of oral cancer may be as high as $76.7 \%$ if detected at stage 0 through oral mucosal examinations, timely oral cancer screening is extremely important. In addition, from the perspective of health promotion, the development of an oral cancer risk model targeted toward the 
high-risk population with smoking and betel nut chewing habits will be beneficial to the improvement of health-related behaviors and reduction in the incidence and mortality rate due to oral cancer among these individuals.

As oral cancer has multiple etiologies and is closely linked to health-related behaviors, the incidence of oral cancer can only be effectively reduced through health education and preventive healthcare in the public. Notably, individuals who have a habit of betel nut chewing may also have concurrent smoking and drinking habits, which may limit the effects arising from the control of a single risk factor, e.g., efforts to curb smoking may result in excessive drinking instead. Therefore, measures targeting the control of multiple risk factors and the reduction of unhealthy lifestyle habits in the public should be considered when formulating health policies.

This study has some limitations. First, only the data pertaining to subjects who fulfilled the requirements of this study were extracted from the national database on cancer screening. Therefore, we could not retrieve data relevant to the parents of the subjects, such as medical history and cancer-related data. This could have affected the predictive ability of the oral cancer incidence risk prediction model established in this study. Second, as the subjects of the present study were selected based on oral cancer screening records, the model established in this study can only be used to predict oral cancer incidence among individuals who fulfill the criteria for oral cancer screening, i.e., individuals who have a habit of smoking or chewing betel nut. Because the oral cancer screening policy at the time did not list drinking habits as a condition for oral mucosal examinations, the present study did not take this factor into consideration. Therefore, the model is not applicable to individuals without smoking and betel nut chewing habits.

\section{Conclusions}

This result clearly indicates that the screening policy is indeed beneficial to the detection of oral cancer at the early clinical stage. In addition, our results showed that the oral cancer incidence rate was significantly higher among betel nut chewers than among smokers and significantly higher among individuals with concurrent habits of smoking and betel nut chewing than among individuals with either habit. Therefore, effective curbing of betel nut chewing should be the priority target in the prevention and control of oral cancer in Taiwan. As the control of a single risk factor produces limited effects, the adoption of measures aimed at controlling multiple risk factors is recommended when formulating health policies $[53,70]$.

Author Contributions: Conceptualization, L.-C.H., P.-T.K., C.-H.L., M.-H.T., S.-A.L., K.-H.H. and W.-C.T.; data curation, L.-C.H., C.-H.L. and L.-T.C.; formal analysis, L.-C.H. and L.-T.C.; funding acquisition, P.-T.K. and W.-C.T.; investigation, C.-H.L., M.-H.T., L.-T.C., K.-H.H. and W.-C.T.; methodology, L.-C.H., P.-T.K., C.-H.L., M.-H.T., S.-A.L., L.-C.H., K.-H.H. and W.-C.T.; project administration, L.-T.C.; resources, P.-T.K., S.-A.L., K.-H.H. and W.-C.T.; software, W.-C.T.; supervision, P.-T.K., C.-H.L., M.-H.T., S.-A.L. and W.-C.T.; validation, C.-H.L., M.-H.T., S.-A.L., L.-C.H. and K.-H.H.; writing - original draft, L.-C.H.; writing - review \& editing, P.-T.K., K.-H.H. and W.-C.T.; final approval of manuscript: all authors; agreement to be accountable for all aspects of the work: all authors. All authors have read and agreed to the published version of the manuscript.

Funding: Our study was supported by the grants (grant numbers CMU107-ASIA-18 and DOH103-HP-1201) from China Medical University and Asia University, as well as the Health Promotion Administration, Taiwan.

Acknowledgments: We are grateful to the Department of Statistics, Ministry of Health and Welfare, Taiwan for providing us with access to the National Health Insurance Research Database and the Oral Cancer Screening Records published by the Health Promotion Administration, Taiwan. We are also grateful to the Health Data Science Center, China Medical University Hospital for providing administrative, technical and funding support.

Conflicts of Interest: The authors declare no conflict of interest. 


\section{References}

1. WHO Cancer Prevention. Available online: https://www.who.int/cancer/prevention/diagnosis-screening/ oral-cancer/en/ (accessed on 20 January 2020).

2. WHO Global Oral Health Programme. Available online: https://www.who.int/oral_health/objectives/en/ (accessed on 20 January 2020).

3. Ferlay, J.; Ervik, M.; Lam, F.; Colombet, M.; Mery, L.; Piñeros, M.; Znaor, A.; Soerjomataram, I.; Bray, F. Global Cancer Observatory: Cancer Today; International Agency for Research on Cancer: Lyon, France, 2018.

4. Oral Health Country Area Profile Project. Available online: https://capp.mau.se/oral-diseases/ (accessed on 20 January 2020).

5. Chaturvedi, A.K.; Anderson, W.F.; Lortet-Tieulent, J.; Curado, M.P.; Ferlay, J.; Franceschi, S.; Rosenberg, P.S.; Bray, F.; Gillison, M.L. Worldwide trends in incidence rates for oral cavity and oropharyngeal cancers. J. Clin. Oncol. 2013, 31, 4550-4559. [CrossRef] [PubMed]

6. Cancer Registry Annual Report, 2016 (Taiwan). Available online: https://www.hpa.gov.tw/Pages/ashx/File. ashx?FilePath $=\sim\{\} /$ File/Attach/10232/File_11658.pdf (accessed on 20 January 2020).

7. Baber, H.; Maqsood, S.; Soomro, M.; Ansari, Z.; Memon, M. Areca Nut Chewing-An Insight. J. Fundam. Appl. Sci. 2017, 9, 1771-1778. [CrossRef]

8. Gupta, V.; Peterson, C.B.; Dice, L.T.; Uchiki, T.; Racca, J.; Guo, J.T.; Xu, Y.; Hettich, R.; Zhao, X.; Rothstein, R.; et al. Sml1p is a dimer in solution: Characterization of denaturation and renaturation of recombinant Sml1p. Biochemistry 2004, 43, 8568-8578. [CrossRef] [PubMed]

9. Vanunu, O.; Magger, O.; Ruppin, E.; Shlomi, T.; Sharan, R. Associating genes and protein complexes with disease via network propagation. PLoS Comput. Biol. 2010, 6, e1000641. [CrossRef]

10. Khawaja, M.R.; Mazahir, S.; Majeed, A.; Malik, F.; Merchant, K.A.; Maqsood, M.; Malik, R.; Ghaffar, S.; Fatmi, Z. Chewing of betel, areca and tobacco: Perceptions and knowledge regarding their role in head and neck cancers in an urban squatter settlement in Pakistan. Asian Pac. J. Cancer Prev. APJCP 2006, 7, 95-100.

11. Auluck, A.; Hislop, G.; Bajdik, C. Gender-and ethnicity-specific survival trends of oral cavity and oropharyngeal cancers in British Columbia. Cancer Causes Control 2012, 23, 1899-1909. [CrossRef]

12. Taj, F.; Tanwir, M.; Aly, Z.; Khowajah, A.A.; Tariq, A.; Syed, F.K.; Waqar, F.; Shahzada, K. Factors associated with non-adherence among psychiatric patients at a tertiary care hospital, Karachi, Pakistan: A questionnaire based cross-sectional study. J. Pak. Med Assoc. 2008, 58, 432-436.

13. Guo, S.-E.; Huang, T.-J.; Huang, J.-C.; Lin, M.-S.; Hong, R.-M.; Chang, C.-H.; Chen, M.-Y. Alcohol, betel-nut and cigarette consumption are negatively associated with health promoting behaviors in Taiwan: A cross-sectional study. BMC Public Health 2013, 13, 257. [CrossRef]

14. De Menezes, R.F.; Bergmann, A.; Thuler, L.C.S. Alcohol consumption and risk of cancer: A systematic literature review. Asian Pac. J. Cancer Prev. 2013, 14, 4965-4972. [CrossRef]

15. IARC Working Group on the Evaluation of Carcinogenic Risks to Humans; World Health Organization; International Agency for Research on Cancer. Tobacco Smoke and Involuntary Smoking; IARC: Lyon, France, 2004; Volume 83.

16. Siegel, R.; Naishadham, D.; Jemal, A. Cancer statistics, 2013. CA Cancer J. Clin. 2013, 63, 11-30. [CrossRef]

17. Clapp, R.W.; Jacobs, M.M.; Loechler, E.L. Environmental and occupational causes of cancer: New evidence 2005-2007. Rev. Environ. Health 2008, 23, 1-38. [CrossRef] [PubMed]

18. Znaor, A.; Brennan, P.; Gajalakshmi, V.; Mathew, A.; Shanta, V.; Varghese, C.; Boffetta, P. Independent and combined effects of tobacco smoking, chewing and alcohol drinking on the risk of oral, pharyngeal and esophageal cancers in Indian men. Int. J. Cancer 2003, 105, 681-686. [CrossRef] [PubMed]

19. Lim, S.S.; Vos, T.; Flaxman, A.D.; Danaei, G.; Shibuya, K.; Adair-Rohani, H.; AlMazroa, M.A.; Amann, M.; Anderson, H.R.; Andrews, K.G. A comparative risk assessment of burden of disease and injury attributable to 67 risk factors and risk factor clusters in 21 regions, 1990-2010: A systematic analysis for the Global Burden of Disease Study 2010. Lancet 2012, 380, 2224-2260. [CrossRef]

20. Mariola, W.; Sebastian, R.; Mateusz, S.; Jacek, K.; Leszek, Z.; Ewa, K.; Jacek, Z.; Andrzej, R.; Wojciech, M.; Krzysztof, B. Lymphocyte-to-monocyte ratio (LMR) is prognostic factor for selection of neoadjuvant treatment in locally advanced rectal cancer patients: Sub-set analysis of Polish-2 study. Ann. Oncol. 2017, 28, 124-125. 
21. Stepanov, I.; Carmella, S.G.; Briggs, A.; Hertsgaard, L.; Lindgren, B.; Hatsukami, D.; Hecht, S.S. Presence of the carcinogen $\mathrm{N}^{\prime}$-nitrosonornicotine in the urine of some users of oral nicotine replacement therapy products. Cancer Res. 2009, 69, 8236-8240. [CrossRef] [PubMed]

22. Warnakulasuriya, S. Causes of oral cancer-an appraisal of controversies. Br. Dent. J. 2009, 207, 471-475. [CrossRef]

23. Mehrtash, H.; Duncan, K.; Parascandola, M.; David, A.; Gritz, E.R.; Gupta, P.C.; Mehrotra, R.; Nordin, A.S.A.; Pearlman, P.C.; Warnakulasuriya, S. Defining a global research and policy agenda for betel quid and areca nut. Lancet Oncol. 2017, 18, e767-e775. [CrossRef]

24. Anaya-Saavedra, G.; Ramírez-Amador, V.; Irigoyen-Camacho, M.E.; García-Cuellar, C.M.; Guido-Jiménez, M.; Méndez-Martínez, R.; García-Carrancá, A. High association of human papillomavirus infection with oral cancer: A case-control study. Arch. Med. Res. 2008, 39, 189-197. [CrossRef]

25. Johnson, N.W.; Warnakulasuriya, S.; Gupta, P.; Dimba, E.; Chindia, M.; Otoh, E.; Sankaranarayanan, R.; Califano, J.; Kowalski, L. Global oral health inequalities in incidence and outcomes for oral cancer: Causes and solutions. Adv. Dent. Res. 2011, 23, 237-246. [CrossRef]

26. Mehanna, H.; Beech, T.; Nicholson, T.; El-Hariry, I.; McConkey, C.; Paleri, V.; Roberts, S. Prevalence of human papillomavirus in oropharyngeal and nonoropharyngeal head and neck cancer-systematic review and meta-analysis of trends by time and region. Head Neck 2013, 35, 747-755. [CrossRef]

27. Meurman, J.H. Infectious and dietary risk factors of oral cancer. Oral Oncol. 2010, 46, 411-413. [CrossRef] [PubMed]

28. Pintos, J.; Black, M.J.; Sadeghi, N.; Ghadirian, P.; Zeitouni, A.G.; Viscidi, R.P.; Herrero, R.; Coutlée, F.; Franco, E.L. Human papillomavirus infection and oral cancer: A case-control study in Montreal, Canada. Oral Oncol. 2008, 44, 242-250. [CrossRef] [PubMed]

29. Westra, W.H. The changing face of head and neck cancer in the 21st century: The impact of HPV on the epidemiology and pathology of oral cancer. Head Neck Pathol. 2009, 3, 78. [CrossRef] [PubMed]

30. Gupta, B.; Kumar, N.; Johnson, N.W. Relationship of lifetime exposure to tobacco, alcohol and second hand tobacco smoke with upper aero-digestive tract cancers in India: A case-control study with a life-course perspective. Asian Pac. J. Cancer Prev. APJCP 2017, 18, 347-356.

31. Ko, Y.-C.; Huang, Y.-L.; Lee, C.-H.; Chen, M.-J.; Lin, L.-M.; Tsai, C.-C. Betel quid chewing, cigarette smoking and alcohol consumption related to oral cancer in Taiwan. J. Oral Pathol. Med. 1995, 24, 450-453. [CrossRef]

32. Warnakulasuriya, S. Global epidemiology of oral and oropharyngeal cancer. Oral Oncol. 2009, 45, 309-316. [CrossRef]

33. Auluck, A.; Walker, B.B.; Hislop, G.; Lear, S.A.; Schuurman, N.; Rosin, M. Socio-economic deprivation: A significant determinant affecting stage of oral cancer diagnosis and survival. BMC Cancer 2016, 16, 569. [CrossRef]

34. Brandt, M.J.; IJzerman, H.; Dijksterhuis, A.; Farach, F.J.; Geller, J.; Giner-Sorolla, R.; Grange, J.A.; Perugini, M.; Spies, J.R.; Van't Veer, A. The replication recipe: What makes for a convincing replication? J. Exp. Soc. Psychol. 2014, 50, 217-224. [CrossRef]

35. Wong, Y.-K.; Tsai, W.-C.; Lin, J.-C.; Poon, C.-K.; Chao, S.-Y.; Hsiao, Y.-L.; Chan, M.-Y.; Cheng, C.-S.; Wang, C.-C.; Wang, C.-P.; et al. Socio-demographic factors in the prognosis of oral cancer patients. Oral Oncol. 2006, 42, 893-906. [CrossRef]

36. Hwang, E.; Johnson-Obaseki, S.; McDonald, J.T.; Connell, C.; Corsten, M. Incidence of head and neck cancer and socioeconomic status in Canada from 1992 to 2007. Oral Oncol. 2013, 49, 1072-1079. [CrossRef]

37. Jemal, A.; Bray, F.; Center, M.M.; Ferlay, J.; Ward, E.; Forman, D. Global cancer statistics. CA Cancer J. Clin. 2011, 61, 69-90. [CrossRef] [PubMed]

38. Cancer Screening Records. Available online: https://www.mohw.gov.tw/dl-15849-9c79d30d-f44e-4404-b582124d841279c7.html (accessed on 20 January 2020).

39. Cancer Registration Records. Available online: https://www.mohw.gov.tw/dl-16047-58258053-4580-493da697-39606fe852b3.html (accessed on 20 January 2020).

40. Akhtar, S. Areca nut chewing and esophageal squamous-cell carcinoma risk in Asians: A meta-analysis of case-control studies. Cancer Causes Control 2013, 24, 257-265. [CrossRef] [PubMed]

41. Akhtar, S.; Sheikh, A.A.; Qureshi, H.U. Chewing areca nut, betel quid, oral snuff, cigarette smoking and the risk of oesophageal squamous-cell carcinoma in South Asians: A multicentre case-control study. Eur. J. Cancer 2012, 48, 655-661. [CrossRef] [PubMed] 
42. Auluck, A.; Hislop, G.; Poh, C.; Zhang, L.; Rosin, M.P. Areca nut and betel quid chewing among South Asian immigrants to Western countries and its implications for oral cancer screening. Rural Remote Health 2009, 9, 1118. [CrossRef] [PubMed]

43. Bell, N.J.; Schuurman, N.; Morad, H.S. A small-area population analysis of socioeconomic status and incidence of severe burn/fire-related injury in British Columbia, Canada. Burns 2009, 35, 1133-1141. [CrossRef] [PubMed]

44. Blot, W.J.; McLaughlin, J.K.; Winn, D.M.; Austin, D.F.; Greenberg, R.S.; Preston-Martin, S.; Bernstein, L.; Schoenberg, J.B.; Stemhagen, A.; Fraumeni, J.F. Smoking and drinking in relation to oral and pharyngeal cancer. Cancer Res. 1998, 48, 3282-3287.

45. Booth, C.M.; Li, G.; Zhang-Salomons, J.; Mackillop, W.J. The impact of socioeconomic status on stage of cancer at diagnosis and survival: A population-based study in Ontario, Canada. Cancer 2010, 116, 4160-4167. [CrossRef]

46. Bunnell, A.; Pettit, N.; Reddout, N.; Sharma, K.; O’Malley, S.; Chino, M.; Kingsley, K. Analysis of primary risk factors for oral cancer from select US states with increasing rates. Tob. Induc. Dis. 2010, 8, 5. [CrossRef]

47. Chu, K.P.; Shema, S.; Wu, S.; Gomez, S.L.; Chang, E.T.; Le, Q.T. Head and neck cancer-specific survival based on socioeconomic status in Asians and Pacific Islanders. Cancer 2011, 117, 1935-1945. [CrossRef]

48. Davies, L.; Welch, H.G. Epidemiology of head and neck cancer in the United States. Otolaryngol. Head Neck Surg. 2006, 135, 451-457.e3. [CrossRef]

49. Johnson, S.; Corsten, M.J.; McDonald, J.T.; Chun, J. Socio-economic factors and stage at presentation of head and neck cancer patients in Ottawa, Canada: A logistic regression analysis. Oral Oncol. 2010, 46, 366-368. [CrossRef] [PubMed]

50. Johnson, S.; McDonald, J.T.; Corsten, M.; Rourke, R. Socio-economic status and head and neck cancer incidence in Canada: A case-control study. Oral Oncol. 2010, 46, 200-203. [CrossRef] [PubMed]

51. Kister Mateusz, P.; Borowska, K.; Kister Karolina, A.; Wojtowicz, A.; Jodlowska-Jedrych, B. Risks associated with betel quid chewing. Curr. Issues Pharm. Med. Sci. 2017, 30, 24-26. [CrossRef]

52. McDonald, J.T.; Johnson-Obaseki, S.; Hwang, E.; Connell, C.; Corsten, M. The relationship between survival and socio-economic status for head and neck cancer in Canada. J. Otolaryngol. Head Neck Surg. 2014, 43, 2. [CrossRef] [PubMed]

53. Muwonge, R.; Ramadas, K.; Sankila, R.; Thara, S.; Thomas, G.; Vinoda, J.; Sankaranarayanan, R. Role of tobacco smoking, chewing and alcohol drinking in the risk of oral cancer in Trivandrum, India: A nested case-control design using incident cancer cases. Oral Oncol. 2008, 44, 446-454. [CrossRef]

54. Pervez, S.; Abro, B. Oral Cancer and Chewing Habits. In Development of Oral Cancer: Risk Factors and Prevention Strategies; Al Moustafa, A.-E., Ed.; Springer: Cham, Switzerland, 2017; pp. 115-132. [CrossRef]

55. Petti, S. Lifestyle risk factors for oral cancer. Oral Oncol. 2009, 45, 340-350. [CrossRef]

56. Sharpe, K.H.; McMahon, A.D.; Raab, G.M.; Brewster, D.H.; Conway, D.I. Association between socioeconomic factors and cancer risk: A population cohort study in Scotland (1991-2006). PLoS ONE 2014, 9, e89513. [CrossRef]

57. Warnakulasuriya, S. Living with oral cancer: Epidemiology with particular reference to prevalence and life-style changes that influence survival. Oral Oncol. 2010, 46, 407-410. [CrossRef]

58. Household Registration Records. Available online: https://www.mohw.gov.tw/dl-17770-e13b366b-822c-4324ba96-a9d76c053c36.html (accessed on 20 January 2020).

59. Deyo, R.A.; Cherkin, D.C.; Ciol, M.A. Adapting a clinical comorbidity index for use with ICD-9-CM administrative databases. J. Clin. Epidemiol. 1992, 45, 613-619. [CrossRef]

60. Ministry of Health and Welfare, Taiwan. List of Catastrophic Illnesses. Available online: https://www.mohw. gov.tw/dl-16096-1b42448d-3306-4270-acaa-722752d564cb.html (accessed on 20 January 2020).

61. Kuchibhotla, S.; Vankayalapati, H.; Yalamanchili, B.; Anne, K.R. ROC analysis of class dependent and class independent linear discriminant classifiers using frequency domain features. In Proceedings of the 2014 International Conference on Advances in Computing, Communications and Informatics (ICACCI), New Delhi, India, 24-27 September 2014; pp. 1916-1920.

62. National Cancer Prevention and Control Program (Third Phase) (Taiwan). Available online: https://www. hpa.gov.tw/Pages/ashx/File.ashx?FilePath=\%7E/File/Attach/1094/File_464.pdf (accessed on 20 January 2020). 
63. Ministry of Health and Welfare, Taiwan. Follow-up Rate for Cases of Positive Results from Oral Cancer Screening, 2018. Available online: https:/www.mohw.gov.tw/dl-55653-662d45e6-0fd2-4bdf-8ac380968e3f9c4c.html (accessed on 20 January 2020).

64. Auluck, A.; Walker, B.B.; Hislop, G.; Lear, S.A.; Schuurman, N.; Rosin, M. Population-based incidence trends of oropharyngeal and oral cavity cancers by sex among the poorest and underprivileged populations. BMC Cancer 2014, 14, 314. [CrossRef]

65. Adrien, J.; Bertolus, C.; Gambotti, L.; Mallet, A.; Baujat, B. Why are head and neck squamous cell carcinoma diagnosed so late? Influence of health care disparities and socio-economic factors. Oral Oncol. 2014, 50, 94-97. [CrossRef]

66. Agarwal, A.K.; Sethi, A.; Sareen, D.; Dhingra, S. Treatment delay in oral and oropharyngeal cancer in our population: The role of socio-economic factors and health-seeking behaviour. Indian J. Otolaryngol. Head Neck Surg. 2011, 63, 145-150. [CrossRef] [PubMed]

67. Gupta, B.; Kumar, N.; Johnson, N.W. A risk factor-based model for upper aerodigestive tract cancers in India: Predicting and validating the receiver operating characteristic curve. J. Oral Pathol. Med. 2017, 46, 465-471. [CrossRef] [PubMed]

68. Oral Cancer Screening Program (Taiwan). Available online: https://www.hpa.gov.tw/Pages/Detail.aspx? nodeid $=1100 \&$ pid $=6461$ (accessed on 20 January 2020).

69. Petersen, P.E. Strengthening the prevention of oral cancer: The WHO perspective. Community Dent. Oral Epidemiol. 2005, 33, 397-399. [PubMed]

70. Feu, D.; Miguel, J.A.M.; Celeste, R.K.; Oliveira, B.H. Effect of orthodontic treatment on oral health-related quality of life. Angle Orthod. 2013, 83, 892-898. [CrossRef] [PubMed]

(C) 2020 by the authors. Licensee MDPI, Basel, Switzerland. This article is an open access article distributed under the terms and conditions of the Creative Commons Attribution (CC BY) license (http://creativecommons.org/licenses/by/4.0/). 